\title{
El mundial desde las periferias
}

\section{The world from the peripheries}

\author{
Claudia Mercedes Jiménez Garcés ${ }^{1}$ \\ Universidad Nacional Abierta y a Distancia, UNAD, Colombia
}

\begin{abstract}
Resumen
Pensar las periferias se convirtió en una posibilidad gracias a los debates que sobre la dependencia se presentaron en América Latina, pero que finalmente permitieron evocar nuevas comprensiones de la realidad desde las particularidades y desde los contextos, situación que promovió las manifestaciones de epistemologías y prácticas de investigación propias y, si se quiere, endógenas. La idea de retomar a las periferias en las representaciones del mundial es un ejercicio para comprender cómo en un colectivo se perfilan sentires nacionales y de identidad global desde miradas particulares, considerando al fútbol como un detonante de la idea de nación.
\end{abstract}

Palabras clave: periferia, fútbol, nación e identidad.

\begin{abstract}
The periphery thinking became a possibility, due to debates about the dependency presented in Latin America, but which, finally, allowed to evoke new understandings of reality from the particularities and contexts. These enviroment promoted the manifestations of epistemologies and own research practices and, endogenous. The idea of return to the peripheries as a representations of the World-Cup is an exercise in to understand how a collective shows national feelings and global identity from a specific views, considering the football as a trigger for the nation meaning.
\end{abstract}

Keywords: periphery, soccer, nation and identity

Recibido: 15 de noviembre de 2014

Aceptado: 16 de diciembre de 2014

Las naciones latinoamericanas heredaron la carga de los episodios épicos del oscurantismo y los revolcones del nacimiento de la razón. A partir de ambos el pensamiento europeo volcó sus deseos más ardientes en la práctica de la esclavitud, servilismo, cuerpo y castigo. De esta manera, América Latina fue vista como un cuerpo salvaje más para dominar, domesticar y adiestrar. En ese afán de purificación se consolidaron los Estados y las nociones de nación que aún se encuentran presentes en las constantes preguntas y resistencia frente a lo que somos.

Desde las banderas del pensamiento racional, se crearon centros de poder que sometían a los marginales a cumplir las promesas de la modernidad: la generación de un capital que les permitiera obtener la libertad tan luchada en el Medioevo. En las fronteras de este centro los despojados, los incultos, los pobres, los que no

1 Socióloga de la Universidad de Nariño. Especialista en Educación, Cultura y Política Universidad Nacional Abierta y a Distancia- UNAD. Maestrante en Género, Sociedad y Políticas de la FLACSO, Argentina. Docente de la UNAD, CEAD Pasto. Integrante de los grupos de investigación "Psicología, Desarrollo Emocional y Educación"y "Cibercultura y territorio". Contacto: cmjimenezg@gmail.com. 
tenían nación luchaban por definirse. Así, para el caso de Colombia, se distribuyeron las riquezas y las pobrezas; las culturas y las ignorancias los que hablan y los que callan, los que dominan y los que obedecen, siendo estos los criterios fundacionales de la nación.

El departamento de Nariño se encontraba en la periferias y en las tensiones de no querer ser parte del centro, sino de ser el centro propio. Esta blasfemia lo condenó a ser tratado históricamente como el más tonto de todo el país; el hijo bobo de toda familia por rebelarse en contra de la razón. Un legado histórico que lo condenó a confinarse en las profundas fronteras del país vecino, en los estrechos márgenes de sus tímida personalidad, entre las montañas que lo encerraban en un cascaron. El proyecto nación no contó con él, así como la modernidad no contó con todos.

Más aún en las luchas por resignificarse, por las resistencias del oprimido, Nariño es una región colombiana que aportó a los procesos de construcción de nación, desde las particularidades culturales de sus carnavales, de sus manifestaciones religiosas y del sentido crítico del humor. Nariño se sintió parte de Colombia, se hizo nación.

Pero faltaba pulir un legado histórico, un odio profundo que condenó al olvido y a la muerte de los nacionales, que no necesitaba del reconocimiento del otro, porque ya no era capaz de reconocerse a sí mismo, y era la posibilidad de sentirse pastuso, de la región, del sur. Uno de los escenarios que permitió el amor por lo propio fue el deporte, y en especial el fútbol. Para ello, el deportivo Pasto, que trascendió la idea del ocio y del entretenimiento comunitario, se convirtió en una herramienta de identidad regional. Ese fue el botón que se apretó para mostrarle a Colombia que desde las particularidades también se podría hablar de nación.

\section{Del fútbol y otros switchs}

Preguntarnos cómo se construye nación implicaría reconocer las condiciones culturales, políti- cas, económicas, ambientales y hasta simbólicas de lo que define identidad nacional. Eso que en Colombia está en proceso de despegue, de limpieza, de un paradigma por resolver. Pero es claro que uno de los elementos que nos lleva a la manifestación de nación desde lo popular es el deporte, particularmente el fútbol.

Pero comenzaré por la definición de identidad desde los grandes debates; para ello citaré a Stuart Hall (2003: 15), para quién el concepto clave no es la identidad sino la identificación que la define como: "un proceso de articulación, una sutura, una sobredeterminación y no una subsunción". Pero si se habla de identidad, el autor concluye que las identidades nunca se unifican. Si estamos en la modernidad tardía, las identidades se encuentran fragmentadas y fracturadas. Muchos de los discursos son prácticas y posiciones diferentes $y$, además, antagónicos:

Uso identidad para referirme al punto de encuentro, el punto de sutura entre, por un lado, los discursos y prácticas que intentan interpelarnos, hablarnos o ponernos en nuestro lugar como sujetos sociales de discursos particulares $y$, por otro, los procesos que producen subjetividades, que nos construyen como sujetos susceptibles de decirse (Hall, 2003: 20).

Para aclarar la idea, invito a Ortiz, quien define a la identidad: "Como una construcción simbólica que se da en relación a un referente, a un interés" (citado en Soto, 2007: 6). Las construcciones subjetivas permiten determinar identidades $y$, desde ellas, definiciones de nación, que parten desde detonadores colectivos, en especial en épocas de crisis. Detengámonos, por ejemplo, en los procesos dictatoriales latinoamericanos, los cuales se construyeron ayudados por un amor patriótico que conformó grandes definiciones de identidad.

Considero, entonces, que el fútbol es uno de esos detonantes para crear identidad, porque despierta los apasionamientos más intensos del colectivo, las construcciones simbólicas más creativas 
y hace manifiesto lo que cotidianamente se silencia. El fútbol es un captador de masas por excelencia, que no solo las seduce sino que además se convierte en uno de los elementos socializadores por excelencia, en las configuraciones de lo local y, bien se podría decir, de procesos de desanclaje local que se globalizan. Hablo del fútbol como elemento simbólico y cultural, y no precisamente como mercado económico, que es una postura que aunque tiene que ver intrínsecamente con el deporte (este aspecto no es necesario abordarlo en el presente texto).

El fútbol, un deporte de masas, también logra generar procesos de glocalización, o como lo precisa Boaventura do Souza, sobre la posibilidad de hablar de globalización desde abajo, en su texto hacia un nuevo sentido común (2009). Esto hace referencia a las formas de resistencia, de participación, de luchas por los derechos humanos, de nuevas subjetividades.

El fútbol es un catalizador de masas, una catarsis colectiva que recoge los sentires sociales que se construyen históricamente y que se naturalizan (como lo diría Norbert Elías). El fútbol es una provocación y eso es seguramente lo que sucede con el Deportivo Pasto: el impulso, la tensión, la crisis, la pulsión que se hace necesaria para reconocerse como pueblo y que sobrepase las dominaciones simbólicas.

Tal vez sea esta una alegoría al romanticismo, pero es una descripción de los rechazos colectivos, una cognición compartida, que evade todo suceso de dominación y de subordinación: aquello que los sujetos y las colectividades logran formar conscientemente.

\section{El mundial de brasil y las fronteras del centro}

Ahora bien, la modernidad se creó sobre la base de los Estados-nación, y por ello convirtió a lo nacional en el centro y fin de toda libertad individual (recordando a Rousseau y su contrato social). El Leviatán, ese mismo que nos propondría nuevas miradas al centro, a las libertades y a la responsabilidad, a la ética y la justicia individual y colectiva, se haría manifiesto en las graderías de estadios invisibles, de hinchas que imaginaron estar en el estadio y gritan a pulmón lleno por su equipo nacional. El profesor David Quitián (2014) define perfectamente la relación entre nación y fútbol:

Por eso los granitos de café, las pelucas del Pibe, los sombreros 'vueltiaos', los ponchos y los colores amarillo, azul y rojo tiñéndolo todo sin pudor delante de las cámaras. La nación desfila por la televisión donde es sobreactuada. La patria se recrea en clave de fútbol y su parodia se inscribe en pentagrama de oda y qué mejor para ello que el himno nacional.

La nación se presentó en nombre del fútbol o, más exactamente, de manera simbólica, efímera, momentánea en los mass media, esos dispositivos que ya se encuentran en nuestros mundos de la vida; o como lo define Habermas: esas colonizaciones, que van definiendo nuestros comportamientos individuales y colectivos.

Nariño, entonces, no fue ajeno a estas apuestas de amor patrio: encarnó el nacionalismo a expensas del fútbol y lo basó en el hecho histórico de pasar a segunda vuelta en el campeonato mundial.

\section{Narración de un hecho histórico}

Caminaba tomada de la mano de la masa, la gente en formaba segundos pisos en camiones y gritaba en apología al carnaval de negros y blancos. Fueron comunes los jvivas! y el orgullo de ser colombiano. Detrás de mí, cariocas (espuma carnavalera), pitos, confeti, papelillos, era un carnaval inédito, pero con otros sentido y con otra razón.

El punto de encuentro, la centralidad urbana, la plaza de Nariño, desfiles y desfiles de camisetas amarillas, gritaban la alegría de un campeonato, de una historia larga de un país en constante duelo. Nariño (el precursor) fue arropado por la tricolor, la amarilla abrazó los brazos que definen al Galeras. 


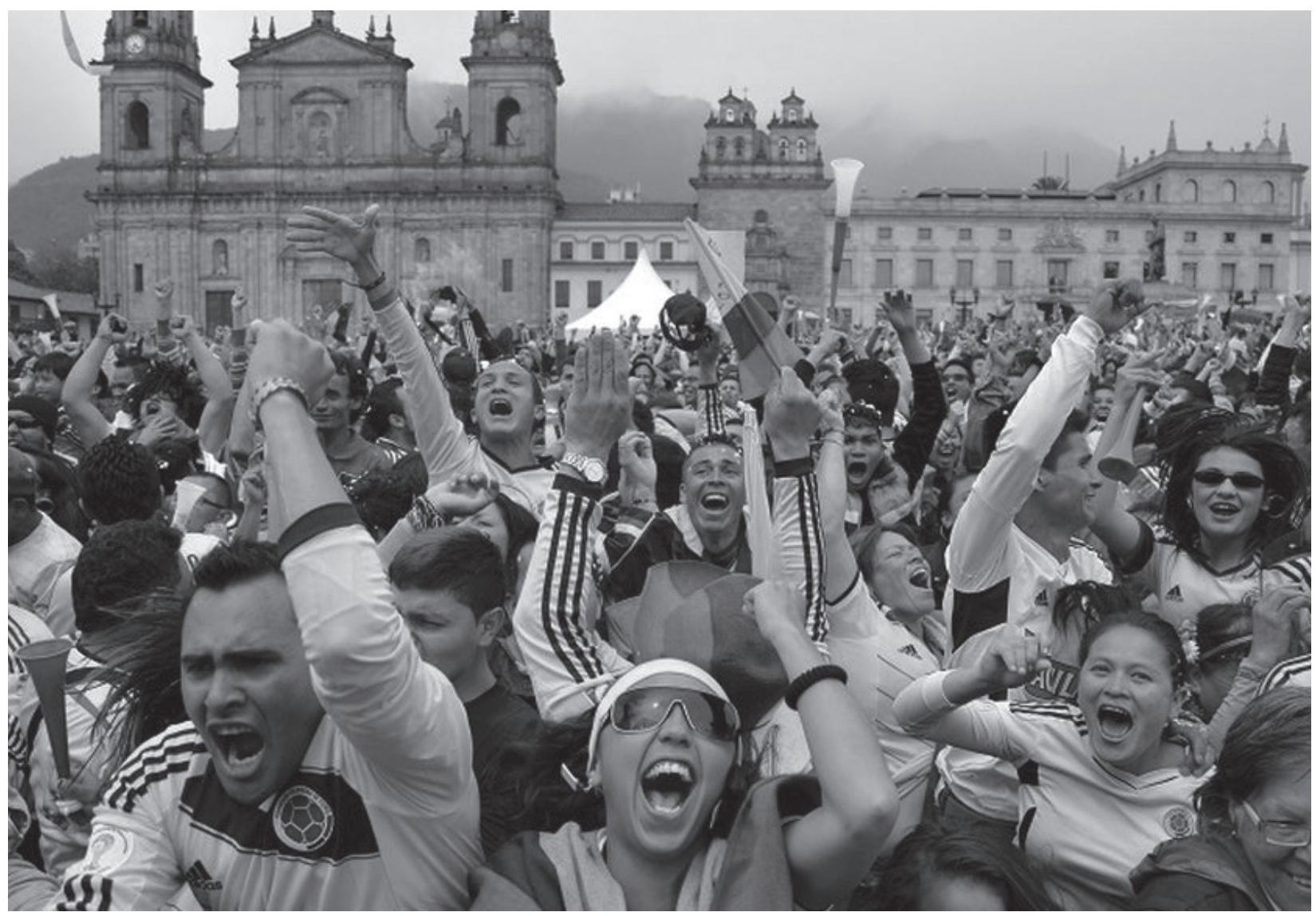

Foto 1: Fuente: $h$ ttp://www.aldia.cr/futbol-internacional/mundial-2014/Seleccion_de_Colombia-aficion-Mundial_Brasil_2014_ ALDIMA20140702_0087_3.jpg

Me pregunto: ¿y qué es fútbol, qué es lo que contagia, qué es lo que atrae tanto y convoca? Me quedo en la esquina observando la gente correr, organizada en cada acera de la calle, como esperando el majestuoso desfile del 6 de enero, y aplauden con euforia cada locura, cada carrera, cada viva, cada bandera que se enviste por la fuerza de los brazos.

\section{Queriendo concluir}

William Ospina, en su libro Los nuevos centros de la esfera, recoge las consideraciones modernas de construcción de centralidades y cómo, a partir de la era global, las centralidades hicieron metástasis y se perfilaron las periferias. "La globalización iba dando dos fases, por un lado la homogenización y por otro lado la resistencia: la globalización como un proceso de intercomunicación planetaria favorece, necesariamente, a quienes tienen más cosas por mostrar y por decir, y la diversidad cultural latinoamericana es una de las más notables" (2000: 50).

Es posible, entonces, comprender que un mundial de fútbol en la era global permite acogidas más íntimas de un deporte netamente popular en el caso de América Latina, y que en un país como Colombia, que enfrenta tensiones sociales complejas, es la válvula de escape de esa euforia colectiva contenida.

Las periferias han cargado simbolismos culturales que han definido las miradas particulares de nación, desde esa Colombia profunda que, como lo diría el profesor Gabriel Restrepo, también es posible sentir desde un encuentro deportivo: manifestaciones de una nacionalidad trastocada, pero con formas de resistencia que persiguen una nueva resignificación. 


\section{Referencias}

Bourdieu, P. (2011) Las estrategias de la reproducción social. Argentina: Siglo XXI Editores.

Bourdieu, P. (2002) Sobre el poder simbólico. En Intelectuales, política y poder. Traducción de Alicia Gutiérrez, Buenos Aires, UBA/ Eudeba, pp. 65-73.

Do Souza, B. (2009) Sociología Jurídica. Hacia un sentido común. Madrid: Editorial Trotta.

Elías, N. \& Dunning, E. (1992) Deporte y Ocio en el proceso de la civilización. Madrid: Fondo de Cultura Económica.
Hall, S. \& Du Gay, P. (2003) Cuestiones de identidad cultural. Buenos Aires: Editorial Amorrortu.

Le Breton, D. (2002) Antropología del Cuerpo y Modernidad. Buenos Aires: Ediciones Nueva Visión.

Quitián, D. (2014) El mundial, la FIFA y los espejismos de nación. Razón Pública, 30 de junio de 2014.

Ospina, W. (2000) Los nuevos centros de la esfera. Bogotá: Punto de Lectura. 
